\title{
Improvements of the Stroke Model Guidelines - Animal body weight and long-term
}

\section{functional concerns}

\author{
Thomas Freret, $\mathrm{PhD}^{*}$ and Valentine Bouet, $\mathrm{PhD}$
}

Groupe Mémoire et Plasticité comportementale, EA4259, Université de Caen basse-Normandie, Caen, France

\begin{abstract}
Despite extensive research efforts in the field of cerebral ischemia, numerous disappointments came out. Indeed, even if experimental studies showed up a huge number of promising drugs, most of them unfortunately failed to be efficient in clinical trials. Based on these reports, factors that play a significant role in causing outcome variation were identified and recently reviewed in the Rodent Stroke Model Guidelines for Preclinical Studies. Herein, we provide improvements to this first edition as regards to the functional evaluation section, especially regarding long-term evaluation. Indeed, as in clinical practice (Rothrock et al 1995), animals display a certain degree of spontaneous recovery after stroke (Hunter et al 1998; Roof et al 2001; Zausinger et al 2000; Zhang et al 2000). Typically, the neurological impairment, assessed by basic items, usually disappears during the initial week following stroke in rodents (Bederson et al 1986). As a contrary, more demanding sensorimotor and cognitive tasks underline other deficits, usually long-lasting. Unfortunately, studies addressing such behavioral impairments are less abundant. Therefore, because the characterization of long-term functional recovery is critical for evaluating the efficacy of potential therapeutic agents in experimental stroke, behavioral tests that proved to be sensitive enough to detect long-term deficits are reported here. Overall, since the ultimate goal of any stroke therapy is the restoration of normal functions, an objective appraisal of the behavioral deficits should be done.
\end{abstract}

Keywords: Acute stroke; animal model; body weight; functional evaluation

\section{Introduction}

We would like to thank all the authors of the first version of 'Stroke model Guidelines'. This manuscript is a very useful and powerful tool, which will allow improving research in the field, and will also help young investigators to choose and develop rodent stroke models in their labs. Nevertheless, from our point of view, some steps that could be helpful especially in regards to the paragraph 8 Functional evaluation, seem to have been omitted or should be more emphasized.

\section{* Correspondence should be sent to:}

Thomas Freret, PhD

GMPc - EA4259, Université de Caen Basse-Normandie,

5 rue Vaubénard, Caen,F-14032, France

Tel/Fax: 0033231947255

Email: thomas.freret@unicaen.fr

Copyright $\odot 2009$ SFES 1939-067X/09

\section{Animal body weight}

The first point to consider is the body weight. Monitoring body weight changes after stroke is indeed of prime importance. Poor nutritional intake may result from (i) reduced consciousness level; (ii) impaired mastication, i.e. unsafe swallow or facial weakness and/or (iii) poor mobility (Dennis 2000; Dittmar et al 2003). It is beyond controversy that several factors are involved in postoperative weight loss, such as anesthesia and the surgical procedure per se. However, origin of other factors does not seem to be completely understood, and literature is not unanimous regarding the graded reduction of body weight. Some of the authors associated loss of body weight with damage of the external carotid artery territory (Dittmar et al 2003), whereas others associated it to the extensive corticostriatal damage itself (Middle cerebral artery territory) (Virtanen et al 2004). Anyhow, weight monitoring is recommended by all authors in the field, since it gives an independent and unambiguous measure of animal welfare and safety. Animals should be weighed at 
least once before surgery and then regularly after at least until initial body weight recovery. Furthermore, accessible to everyone and not only to behaviorists since it does not require any specific skill, this parameter can give also, in some ways, information on how animals recover from surgery and can even be a prognostic index for functional outcome. Interestingly, clinical observations, notably from the FOOD clinical trial (FOOD Trial Collaboration 2003), have associated poor nutritional status to poor outcome after stroke. Similarly, a negative effect of both malnutrition and dehydration has been observed on functional outcome after stroke (Davalos et al 1996). Thus, even if a strong causal link is not so obvious, Jonsson and colleagues suggested that body weight monitoring may be useful, particularly among patients with severe stroke (Jonsson et al 2008). Besides, Dennis demonstrated that patients' nutritional status often deteriorates after stroke because metabolic demands cannot be satisfied due to feeding difficulties (Dennis 2000). As regards to experimental studies, Dittmar and colleagues demonstrated that impaired mastication and swallowing functions restricted ingestion and resulted in worse motor performance (Dittmar et al 2003).

\section{Long-term functional concerns}

In animal, the functional evaluation during the early hours following stroke are often misstated by surgery and anesthetics used. Therefore, 2-6 hours postocclusion is a conflicting period. Thus, a long-term evaluation has to be considered. Moreover, such long-term studies have been highly recommended during the Stroke Therapy Academic Industry Roundtable (Fisher et al 2007; Green 2002; 1999; Wahlgren \& Ahmed 2004). Indeed, as in clinical practice (Rothrock et al 1995), animals display a certain degree of spontaneous recovery within the short time after experimental cerebral ischemia (Hunter et al 1998; Roof et al 2001; Zausinger et al 2000; Zhang et al 2000). Although more demanding sensorimotor and cognitive tasks are powerful to reveal tiny deficits, long-term studies addressing such behaviors are unfortunately less abundant. The characterization of long-term functional recovery is however critical for evaluating the efficacy of potential therapeutic agents in experimental stroke. Indeed, both acute (few days) and long-term (several weeks or months) evaluations have to be addressed in order to demonstrate a stable neuroprotection, and not only a slowing of the lesion maturation (Corbett \& Nurse 1998; Valtysson et al 1994). The issue of including behavioral assessment in animal stroke studies becomes even more critical with the recent interest in neurorestorative strategies, which require a longer time window of administration than classical treatments. Indeed, their effectiveness is more likely observable by changes in synapse number and dendritic structure for example, than by changes in infarct volume (Biernaskie \& Corbett 2001; Kawamata et al 1996). Thus, since the ultimate goal of any stroke therapy is the restoration of normal functions of the patient, an objective appraisal of the behavioral deficits should be done. To this end, several behavioral tests have been applied to ischemia in regards to clinical criteria, from the most simple which measures global neurological status or motor reflexes (i.e. neurological score (Bederson et al 1986), limb placing test (De Ryck et al 1989), chimney test, cylinder test (Bouet et al 2007)) - those tests would be mostly useful to assess acute phase after stroke, basically from 1 to 7 days) to more complex ones assessing both sensory and motor functions (i.e. adhesive removal (Bouet et al 2009), rotarod or staircase (Bouet et al 2007; Freret et al 2009; Freret et al 2006; Grabowski et al 1993; Modo et al 2000; Rogers et al 1997), which are conversely more relevant for long-term phase). Similarly, the memory tests have been developed to investigate cognitive functions (i.e. passive avoidance test, learning strategies - Morris water maze (Borlongan et al 1995; Bouet et al 2007; Freret et al 2009; Winter et al 2005) and would be preferentially used for later time points since they require minimal motor function). Stroke-induced functional impairments can be divided into acute (where the effect of drugs on the rate of recovery could be pointed out) and long-termed (where the effects of treatments on the extent of recovery could be appreciated). Ideally, a set of tests (at least one for each phase, acute and long-term) has to be performed to gather complementary information. Those behavioral tests have to be carefully chosen in accordance with the drugs tested, that is the time at which an effect is expected (acute or long-term stage after ischemic event) and the nature of the targeted cerebral structures. Indeed, since stroke damages various anatomical and functional regions of the brain with a different timescale, and because those regions may be also differentially affected by treatments, it is our view and that of others (Virley et al 2000) that direct (cortex, striatum) or indirect (thalamus) anatomical substrates hit during stroke, rather than global brain lesion, may be critical determinants of behavioral impairment and outcome.

In the same way of thoughts, whereas the correlation between acute histological lesion and early behavioral impairment is well documented (Rogers et al 1997), less is known about the long-term evolution of this relationship. Moreover, those correlation 
studies have to take into account the different brain structures affected by stroke in order to bring a better understanding of their involvement in behavioral impairments (Grabowski et al 1993; Hudzik et al 2000). Basically, direct and indirect methods are unanimously admitted for estimating lesion volume both in the whole brain or for each cerebral structure. Their use depends on the time elapsed since the stroke event. Thus, for studies performed in an acute time frame, the lesion volume can be assessed by multiplying infarcted area by the distance between sections - direct method. Nevertheless, lesion volumes should be then corrected according to the volume of the edema. As regards to long-term studies and because of the disappearance of the necrotic area leading to a cystic zone, the lesion volume is frequently measured according to an indirect method. This method consists in calculating the difference between the remaining healthy ipsilateral hemisphere and the contralateral one, and then by multiplying infarcted area by the distance between sections (Grabowski et al 1993).

The use of clinically relevant models taking into account associated factors and/or pathologies (i.e. aging, arterial hypertension, diabetes, ..) has to be reinforced. Indeed, the post-ischemic recovery may be different, depending on the presence of these aggravating factors. For instance, the majority of animal experiments - examining the pathophysiology and treatment of stroke, often consider relatively young animals (few weeks of age). However, in accordance to the great amount of recent findings in the field of aging (Lindner et al 2003; Nyberg \& Waller 1989), it would be of a prime importance to investigate functional recovery in animal models integrating those aggravating factors.

\section{References}

Bederson JB, Pitts LH, Tsuji M, Nishimura MC, Davis RL, Bartkowski H. 1986. Rat middle cerebral artery occlusion: evaluation of the model and development of a neurologic examination. Stroke 17:472-6

Biernaskie J, Corbett D. 2001. Enriched rehabilitative training promotes improved forelimb motor function and enhanced dendritic growth after focal ischemic injury. J Neurosci 21:5272-80

Borlongan CV, Cahill DW, Sanberg PR. 1995. Locomotor and passive avoidance deficits following occlusion of the middle cerebral artery. Physiol Behav. 58:909-17.

Bouet V, Boulouard M, Toutain J, Divoux D, Bernaudin M, et al. 2009. The adhesive removal test: a sensitive method to assess sensorimotor deficits in mice. Nat Protoc 4:1560-4

Bouet V, Freret $T$, Toutain J, Divoux D, Boulouard $M$, Schumann-Bard P. 2007. Sensorimotor and cognitive deficits after transient middle cerebral artery occlusion in the mouse. Exp Neurol 203:55567

Corbett D, Nurse S. 1998. The problem of assessing effective neuroprotection in experimental cerebral ischemia. Prog Neurobiol 54:531-48

Davalos A, Ricart W, Gonzalez-Huix F, Soler S, Marrugat J, et al. 1996. Effect of malnutrition after acute stroke on clinical outcome. Stroke 27:1028-32

De Ryck M, Van Reempts J, Borgers M, Wauquier A, Janssen PA. 1989. Photochemical stroke model: flunarizine prevents sensorimotor deficits after neocortical infarcts in rats. Stroke 20:1383-90

Dennis M. 2000. Nutrition after stroke. Br Med Bull 56:46675

Dittmar M, Spruss T, Schuierer G, Horn M. 2003. External carotid artery territory ischemia impairs outcome in the endovascular filament model of middle cerebral artery occlusion in rats. Stroke 34:2252-7

Fisher M, Hanley DF, Howard G, Jauch EC, Warach S. 2007. Recommendations from the STAIR $V$ meeting on acute stroke trials, technology and outcomes. Stroke 38:245-8

FOOD Trial Collaboration 2003. Poor nutritional status on admission predicts poor outcomes after stroke: observational data from the FOOD trial. Stroke 34:1450-6

Freret T, Bouet V, Leconte C, Roussel S, Chazalviel L, et al 2009. Behavioral deficits after distal focal cerebral ischemia in mice: Usefulness of adhesive removal test. Behav Neurosci 123:224-30

Freret $\mathrm{T}$, Chazalviel L, Roussel S, Bernaudin $\mathrm{M}$, Schumann-Bard P, Boulouard M. 2006. Long-term functional outcome following transient middle cerebral artery occlusion in the rat: correlation between brain damage and behavioral impairment. Behav Neurosci 120:1285-98

Grabowski M, Brundin P, Johansson BB. 1993. Pawreaching, sensorimotor, and rotational behavior after brain infarction in rats. Stroke 24:889-95

Green AR. 2002. Why do neuroprotective drugs that are so promising in animals fail in the clinic? An industry perspective. Clin Exp Pharmacol Physiol 29:1030-4

Hudzik TJ, Borrelli A, Bialobok P, Widzowski D, Sydserff S, et al. 2000. Long-term functional end points following middle cerebral artery occlusion in the rat. Pharmacol Biochem Behav 65:553-62

Hunter AJ, Mackay KB, Rogers DC. 1998. To what extent have functional studies of ischaemia in animals been useful in the assessment of potential neuroprotective agents? Trends Pharmacol Sci 19:59-66

Jonsson AC, Lindgren I, Norrving B, Lindgren A. 2008. Weight loss after stroke: a population-based study from the Lund Stroke Register. Stroke 39:918-23

Kawamata T, Alexis NE, Dietrich WD, Finklestein SP. 1996. Intracisternal basic fibroblast growth factor (bFGF) enhances behavioral recovery following focal cerebral infarction in the rat. $\mathrm{J}$ Cereb Blood Flow Metab 16:542-7

Lindner MD, Gribkoff VK, Donlan NA, Jones TA. 2003. Long-lasting functional disabilities in middle-aged 
rats with small cerebral infarcts. J Neurosci 23:10913-22

Modo M, Stroemer RP, Tang E, Veizovic T, Sowniski P, Hodges H. 2000. Neurological sequelae and longterm behavioural assessment of rats with transient middle cerebral artery occlusion. $J$ Neurosci Methods. 104:99-109.

Nyberg P, Waller S. 1989. Age-dependent vulnerability of brain choline acetyltransferase activity to transient cerebral ischemia in rats. Stroke 20:495-500

Rogers DC, Campbell CA, Stretton JL, Mackay KB. 1997. Correlation between motor impairment and infarct volume after permanent and transient middle cerebral artery occlusion in the rat. Stroke 28:2060-5; discussion 6

Roof RL, Schielke GP, Ren X, Hall ED. 2001. A comparison of long-term functional outcome after 2 middle cerebral artery occlusion models in rats. Stroke 32:2648-57

Rothrock JF, Clark WM, Lyden PD. 1995. Spontaneous early improvement following ischemic stroke. Stroke 26:1358-60

STAIR. 1999. Recommendations for standards regarding preclinical neuroprotective and restorative drug development. Stroke 30:2752-8

Valtysson J, Hillered L, Andine P, Hagberg H, Persson L. 1994. Neuropathological endpoints in experimental stroke pharmacotherapy: the importance of both early and late evaluation. Acta Neurochir (Wien) 129:58-63

Virley D, Beech JS, Smart SC, Williams SC, Hodges $H$, Hunter AJ. 2000. A temporal MRI assessment of neuropathology after transient middle cerebral artery occlusion in the rat: correlations with behavior. $J$ Cereb Blood Flow Metab 20:563-82

Virtanen T, Jolkkonen J, Sivenius J. 2004. Re: External carotid artery territory ischemia impairs outcome in the endovascular filament model of middle cerebral artery occlusion in rats. Stroke 35:e9-10; author reply e9-

Wahlgren NG, Ahmed N. 2004. Neuroprotection in cerebral ischaemia: facts and fancies--the need for new approaches. Cerebrovasc Dis 17 Suppl 1:153-66

Winter B, Juckel G, Viktorov I, Katchanov J, Gietz A, et al. 2005. Anxious and hyperactive phenotype following brief ischemic episodes in mice. Biol Psychiatry. 57:1166-75.

Zausinger S, Hungerhuber $\mathrm{E}$, Baethmann A, Reulen $\mathrm{H}$, Schmid-Elsaesser R. 2000. Neurological impairment in rats after transient middle cerebral artery occlusion: a comparative study under various treatment paradigms. Brain Res 863:94-105

Zhang L, Chen J, Li Y, Zhang ZG, Chopp M. 2000. Quantitative measurement of motor and somatosensory impairments after mild (30 min) and severe $(2 \mathrm{~h})$ transient middle cerebral artery occlusion in rats. J Neurol Sci 174:141-6 